\title{
Evaluation and Psychoeducational Intervention of Learning Disabilities: A Case Study
}

\author{
Isaias Martin-Ruiz ${ }^{1,2, *}$, Maria-Jose Gonzalez Valenzuela ${ }^{1,2}$, Inmaculada Jordan-Galera ${ }^{2}$ \\ ${ }^{1}$ Department of Developmental and Educational Psychology, Faculty of Psychology and Speech Therapy, University of Málaga, \\ Campus de Teatinos, s/n. 29071 Málaga, Spain \\ ${ }^{2}$ Research Group Andalusian SEJ-521 "Learning Disabilities and Development Disorders", Spain
}

Received May 24, 2021; Revised August 4, 2021; Accepted August 27, 2021

\section{Cite This Paper in the following Citation Styles}

(a): [1] Isaias Martin-Ruiz, Maria-Jose Gonzalez Valenzuela, Inmaculada Jordan-Galera, "Evaluation and Psychoeducational Intervention of Learning Disabilities: A Case Study," Universal Journal of Educational Research, Vol. 9, No. 9, pp. 1699 - 1712, 2021. DOI: 10.13189/ujer.2021.090910.

(b): Isaias Martin-Ruiz, Maria-Jose Gonzalez Valenzuela, Inmaculada Jordan-Galera (2021). Evaluation and Psychoeducational Intervention of Learning Disabilities: A Case Study. Universal Journal of Educational Research, 9(9), 1699 - 1712. DOI: 10.13189/ujer.2021.090910.

Copyright@2021 by authors, all rights reserved. Authors agree that this article remains permanently open access under the terms of the Creative Commons Attribution License 4.0 International License

\begin{abstract}
Learning Disabilities are one of the most frequent deficits in the teaching and learning process, present between 5 and $15 \%$ of the students. Various definitions have been made, such as DSM 5, ICD-11, or other more psychoeducational definitions. The main problem is the unexpected difficulties in learning how to read or write despite having a medium intellectual capacity. Deficits can be found in: cognitive variables, visual perceptual processing, phonological processing, semantic processing, and morphosyntactic processing. The purpose of this paper is to identify the reading and writing learning disabilities of a Spanish-speaking subject. The methodology is a single case study, which is examined of a 7-year-old boy enrolled in the second year of Primary Education at a grant-maintained school in the city of Malaga (Spain). A psychoeducational evaluation proposal is described with different qualitative and quantitative techniques. The results indicate that the subject presents difficulties in his acquisition of Reading and Writing skills, showing signs of cognitive deficits in memory, attention, processing speed, visual and phonological processing, and difficulties in reading and writing. Finally, a proposal for psychoeducational intervention is described, which would be useful in promoting learning and improving the pupil's academic performance. The research shows the relevance of the global evaluation of cognitive and psycho-linguistic variables and the need to establish an early diagnosis. It is also necessary to highlight the relevance of early intervention and the establishment of clear educational
\end{abstract}

guidelines towards the teacher and the family. The main limitations are determined from the single case study and the possible limitations of validity and generalizability of this study to other languages.

Keywords Learning Disabilities, Reading, Writing, Attention, Processing Speed, Memory, Visual and Phonological Processing

\section{Introduction}

Learning how to read and write is one of the most important tasks undertaken at school, and mastering literacy is a fundamental element in academic success [1]. Reading and writing are functional skills, essential for learning other areas and content. However, around $74 \%$ of the pupils do not have an intermediate grasp of literacy by the end of Secondary Education, and more than 22 and $23 \%$ have a poor or very poor grasp on OECD countries and Spain, respectively [2].

Some pupils have problems with learning how to read and write from the very start of their literacy learning journey, presenting numerous disabilities of reading and writing, including dyslexia. Pupils with Learning Disabilities (LD) range from 5 to $17.5 \%$ of the population in compulsory schooling, depending on the definitions and classifications used [3-6]. Prevalence also depends on 
the transparency and granularity of spelling systems, and LD are more frequent in opaque languages [6-7]. In transparent languages such as Spanish, it can range from 3 to $7 \%$ of the population [8-10].

LD are considered a Special Educational Need (SEN) under Spanish law, but are not considered as disability, as is the case in other countries [11-12].

The most widely supported definition of LD today is set out by the National Joint Committee of Learning Disabilities (NJCLD), which has several editions. In particular, the NJCLD [13-15] points out that the general term LD refers to a heterogeneous group of disorders manifested through significant difficulties in acquiring and using skills to listen, speak, read, write, reason, or solve mathematical problems. These disorders are intrinsic to the subject, presumably due to central nervous system dysfunction, which can occur throughout life. Although LDs can occur concomitantly with other disabilities (for example, intellectual development disorder, severe emotional disorders) or with extrinsic influences, they are not the result of these conditions or influences.

The definition sets out the areas that may present deficits (speech, reading, writing, reasoning, and mathematics), indicating that the origin is intrinsic and neurological. It also notes that the persistence of LDs occurs throughout the life cycle and not only in childhood [12, 16-17]. Problems of self-control, perception, and social interaction, as deficits that are not part of the concept of LD but are concomitant thereto, as well as differential diagnosis with other disorders or contextual deficits are also noted.

From a more descriptive perspective, the Diagnostic and Statistical Manual of Mental Disorders 5 [18] as well as the International Classification of Disease 11 [19] point out that Specific Learning Disabilities are neurodevelopmental disorder, along with other disabilities. The DSM-5 definition (see Table 1) presents certain incorporations and amendments with respect to previous editions. One of them is the incorporation of the term "specific", to emphasise the importance of attributing the diagnosis to a specific area or aptitude, that is, to the sublexical processes of literacy (accuracy or fluency in reading and/or writing), to supralexical processes (reading comprehension and/or writing composition), or mathematics (mathematical calculation and reasoning). Another new development is the inclusion of the term dyslexia, as a disability that affects the accuracy and fluency of reading and writing with or without a deficit in reading comprehension or written expression.

Table 1. Nosological description of LD, according to DSM- 5 [18]

A. Difficulty in learning and using academic skills, evidenced by the presence of at least one of the following symptoms that have persisted for at least 6 months, despite interventions targeting these difficulties:

1. Difficulty in reading (e.g., inaccurate, slow, and only with much effort, in other words, reads individual words aloud incorrectly or hesitantly, often guesses words, difficulty expressing words well).

2. Difficulty in understanding the meaning of what is read (e.g., can read a text accurately, but does not understand the sentence, relationships, inferences, or deeper meaning of what has been read).

3. Spelling difficulties (e.g., might add, omit, or replace vowels or consonants).

4. Difficulties with written expression (e.g., makes multiple grammatical or punctuation errors in a sentence; poor paragraph organisation; written expression of ideas is unclear).

5. Difficulties in mastering numeric sense, numeric data, or calculation (e.g., misunderstands numbers, their magnitude, and their relationships; uses fingers to add single-digit numbers instead of remembering mathematical operations as their peers do; becomes lost when performing arithmetic calculation and might swap procedures around).

6. Difficulties with mathematical reasoning (e.g., has great difficulty in applying mathematical concepts, facts, or operations to solve quantitative problems).

B. Academic skills are substantially affected, quantifiably below what is expected according to the individual's chronological age, and significantly interfere with academic or work performance, or with activities of daily living, as confirmed by standardised, individually administered measurements (tests) and a comprehensive clinical evaluation. In individuals aged 17 and older, the documented history of learning disabilities can be replaced by standardised assessment.

C. Learning disabilities begin at school age but might not fully manifest until the demands of the affected academic skills exceed the individual's limited abilities (e.g., in set examinations, reading or writing complex and long reports for an undeferrable deadline, very large amounts of schoolwork).

D. Learning disabilities are not best explained by intellectual disabilities, uncorrected visual or hearing disorders, other mental or neurological disorders, psychosocial adversity, lack of the language of academic instruction, or inadequate educational guidelines. 
In general, it can be said that subjects with learning disabilities are a heterogeneous group of individuals who display a recoverable delay in development and whose academic performance in reading, writing and mathematics, in teaching-learning situations (intentional and conscious processes), is ostensibly below that of their age and even ability. Based on this there would presumably be deficiencies in basic psychological processes: memory, attention, perception, language, metacognition, and social cognition (self-esteem, self-concept, social interaction, motivation...). In this regard, they are subjects that are inadequately adapted to the demands of their school, family, and social environment, presenting difficulties when it comes to solving problems or achieving goals that arise daily and throughout their lives $[16,20]$.

From a psychoeducational perspective, the concept of Learning Disabilities refers to a number of features $[16$, 20], including:

- Heterogeneous group.

- Difficulties in adapting to the education system.

- Difficulties in acquiring new knowledge, skills, or strategies.

- Difficulties in solving academic problems or tasks.

- Deficiencies in learning strategies (use, awareness, and speed).

- Minor developmental delay.

- Problems in psychological processes: attention, memory, perception, linguistic, reasoning, social cognition, and metacognition.

- IQ-performance discrepancy; age-performance discrepancy; verbal understanding-performance discrepancy.

- Difficulties may appear throughout the life cycle.

- Normal Intelligence.

- Practical intelligence problems.

- They do not respond to early treatment.

- Difficulties not caused by intellectual development delay, sensory and motor deficits, socio-emotional maladjustment, or sociocultural deficiencies.

- Existence of neurological dysfunctions.

Reading and writing learning disabilities (RWLD) have a multi-causal origin, and various factors can intervene in the appearance, development, and endurance of deficits. Various RWLD theories have proposed different explanations about the genetic, neurological, behavioural, perceptual, verbal, cognitive, metacognitive, emotional, and motivational origins, such as theories that include the role of the school and family context [6, 16, 21-23].

The subject variables involved in RWLD could be summarised in five areas, which should be explored to determine the degree of deficits present. They are: cognitive variables, visual perceptual processing, phonological processing, semantic processing, and morphosyntactic processing [5-6, 20, 22].

Cognitive variables, and especially cognitive processes of attention, memory, and processing speed, play an important role in literacy processes, as they are basic learning skills related to basic psychological processes. We also need to know an individual's intellectual capacity in order to establish a differential diagnosis with intellectual disability [5].

Secondly, the role of visual perceptual processing must be established since, on certain occasions, subjects show deficits in the perception and integration of temporal-spatial processes, such as hand-eye coordination, figure-background discrimination, constancy of form, and position in space and spatial relations [24-25].

Phonological processing is extremely relevant to reading processes, especially in subjects with LDs. Phonological development plays a decisive role in the ability to articulate and discriminate between different phonemes, and subjects with speech disorders are more likely to present RWLD [5-6]. Phonological awareness is related to the ability to operate with speech segments and is necessary for grapheme and phoneme conversion. It is also the most widely used variable in the detection of RWLD and is the predictor variable with the lowest false-negative ratio $[17,26]$.

Semantic processing is also related to deficits in literacy, as subjects with LDs make inefficient use of semantic coding for word recognition, limiting the possibility of increasing their known lexicon and making reading comprehension difficult $[16,20]$ Finally, morphosyntactic processing also presents significant deficits in pupils with LDs, as they cannot effectively understand sentences with complex syntax or detect grammatical errors $[16,20]$.

Therefore, the objective of this work is to conduct a psychoeducational evaluation of a pupil who presents difficulties in learning how to read and write, and to offer a proposal for psychoeducational intervention in accordance with the variables and areas affected.

\section{Materials and Methods}

\subsection{Research Design}

This article presents a single case study research or replication design. It is characterised by the successive monitoring of a single case study, used in both basic and applied research, of a therapeutic nature related to evaluation, diagnosis, and intervention [25].

The single case design aims to record the behaviour of a subject in controlled situations, which used in applied research for the evaluation and diagnosis of a clinical case, as well as to record changes in the applications of psychological interventions [26]. The single case design investigates the causes that affect the variability of the recorded behaviour using questionnaires or tests as well as the control of strange or alien variables that may affect the 
diagnosis or the effectiveness of the treatment, achieving high validity rates internal [25].

\subsection{Sample}

The subject is a Spanish-speaking boy aged 7 years and 6 months old, from the city of Malaga (Spain). The subject is currently enrolled in the second year of Compulsory Primary Education. The family setting includes two older half-brothers (from a different father), and a mother who is single and unemployed, with a primary level of education. It is a large family, with many financial problems, since the only income the family receives is the Disability Allowance granted to the brother.

\subsection{Methodology}

The case study follows the psychoeducational evaluation and intervention procedure in six steps for the early detection of dyslexia [5].

The evaluation procedure begins with the detection of deficits in literacy learning, once the teaching and learning processes have begun within ordinary instruction.

Having observed that the pupil is not making progress in learning how to read and write, the assessment procedure set out in Table 2 is implemented.
The first step includes an interview with the parents to gather information in terms of the subject's development (biological, motor, sensory, social, communicative-linguistic) and the family setting (family history, family organisation, expectations about the child's difficulties, family impact of the child's difficulties).

The second stage involves conducting a structured interview with the teacher to find out the problems their pupil might present, his personal development (motor, sensory, social, communicative-linguistic, style of learning and motivation), the classroom climate (class organisation, position of the pupil within the classroom, materials used by the pupil, the pupil's integration in the classroom) and his school record (schools attended, academic performance, diversity management measures received, and approach to schooling).

The third phase consists of an individual assessment of the subject with the aim of determining the subject's level of intelligence and ruling out any other comorbid pathology.

The fourth step is to establish the difficulties he presents regarding literacy, both in reading accuracy and fluency and in writing accuracy.

Fifthly, the cognitive and linguistic variables that explain the appearance of RWLD should be evaluated.

Finally, if necessary, an assessment is carried out of any other concomitant deficits the subject may present.

Table 2. Stages of the third phase of RWLD evaluation [5]

\begin{tabular}{|c|c|c|c|}
\hline \multicolumn{2}{|c|}{ Stage } & Content & Technique \\
\hline $\mathbf{1}$ & Interview with the parents & $\begin{array}{c}\text { Information, indications } \\
\text { Informed consent for evaluation } \\
\text { Development } \\
\text { Family setting }\end{array}$ & Interviews \\
\hline $\mathbf{2}$ & Interview with the teacher & $\begin{array}{c}\text { Problem description } \\
\text { Development } \\
\text { Academic record }\end{array}$ & WISC \\
\hline $\mathbf{3}$ & Measure of Intelligence & Administer test of intelligence & LEE \\
\hline $\mathbf{4}$ & Measure of Reading and Writing & $\begin{array}{c}\text { Reading fluency } \\
\text { Reading comprehension } \\
\text { Writing accuracy }\end{array}$ & WISC \\
\hline $\mathbf{5}$ & Cognitive-Linguistic Measure & $\begin{array}{c}\text { Phonological awareness, } \\
\text { Knowledge of the alphabet, } \\
\text { Naming speed, } \\
\text { Short-term memory, }\end{array}$ & ITPA \\
\hline $\mathbf{6}$ & & Other disorders & Evaluate other symptoms or deficits \\
\end{tabular}




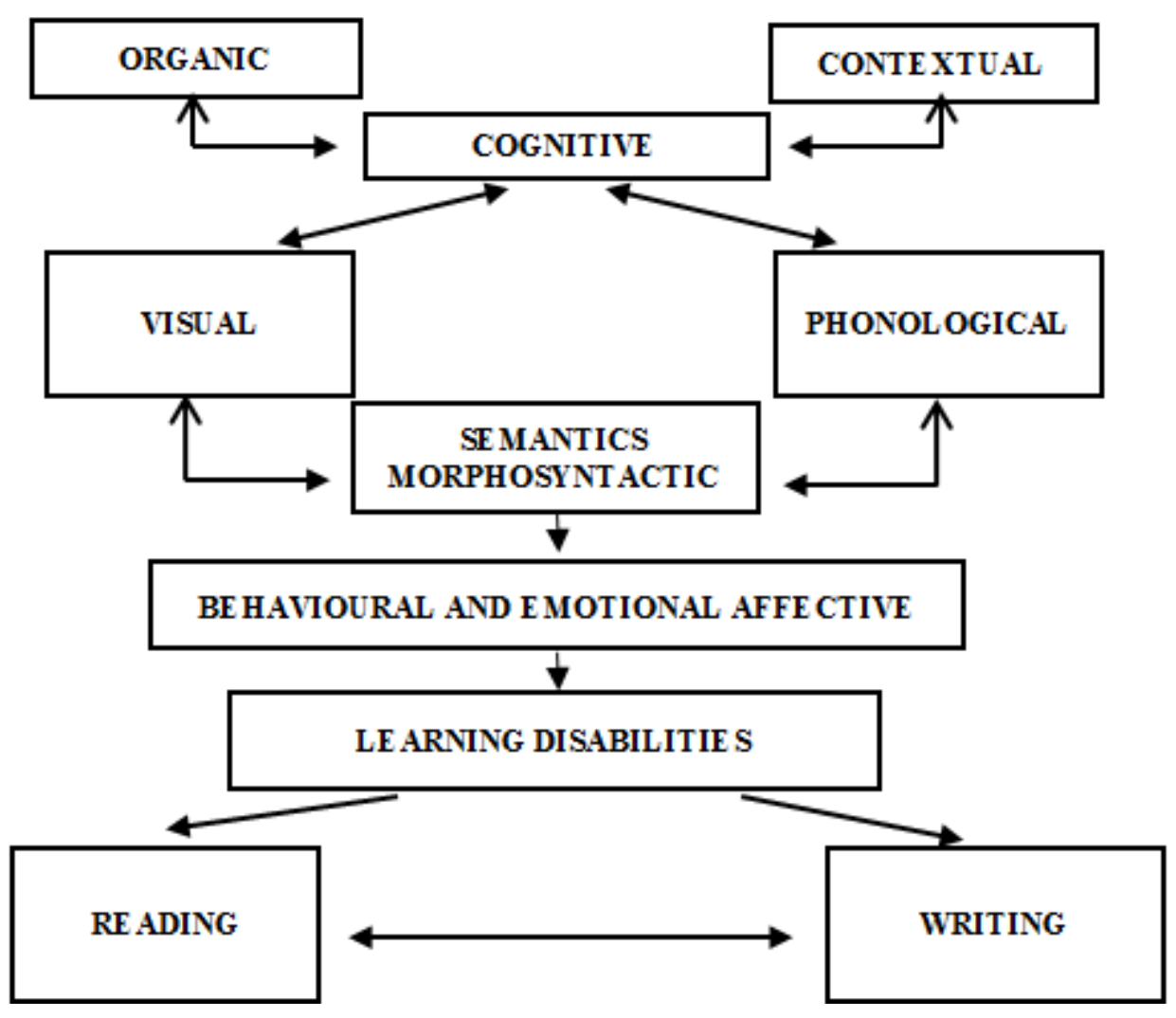

Figure 1. Integration of results and diagnosis

By using all the variables possibly involved in the appearance of RWLD, a model is presented that integrates the results and determines diagnosis, as shown in the diagnostic schematic presented in Figure 1.

Figure 1 includes information about the organic and contextual variables of the subject. These first reports should include information from interviews with parents and teachers regarding the subject's organic variables, school history, and contextual history. Then, information is included about intelligence and cognitive processes of attention, memory, etc. It also includes information on visual and phonological processing, mainly errors in the visual route and phonological route. Results regarding the subject's semantic and morpho-syntactic processing are then reported. Results about behavioural, emotional, and motivational variables are also indicated. Finally, deficits in writing and reading are described.

\subsection{Instrument}

In this evaluation process, a performance evaluation is carried out for reading and writing, subject variables and contextual variables that could influence the child's development. A number of qualitative and other quantitative techniques are used for this purpose.

\subsubsection{Qualitative techniques}

Interview with the family. The interview conducted provides more comprehensive information about the child's family upbringing and his relationships and behaviours within the family. It also allows us to investigate the root cause of this pupil's potential difficulties.

Interview with the teacher. The interview conducted provides information about the child's actions in the classroom, the kinds of difficulties he presents according to his teacher and so on, in order to explore the perspective of the person in charge of the child's learning at school.

\subsubsection{Qualitative Techniques}

\subsubsection{Wechsler Intelligence Scale for Children (WISC- V)}

The WISC-V [27] is used to measure the overall thinking and reasoning skills of children between 6 and 16 . It has a reliability of 0.88 and a validity of 0.80 . The test is made up of four scales: verbal comprehension (similarities, vocabulary, understanding, information and guessing), perceptual reasoning (cubes, concepts, Matrices, Incomplete figures), working memory (digits, letters and numbers, and arithmetic) and Processing Speed (coding, symbol search and animals).

The test is divided into 10 mandatory sub-tests and a further 5 optional sub-tests.

\subsubsection{Reading and Writing in Spanish Test (LEE)}

The LEE test [28] evaluates word reading and writing procedures. It shows how a child develops in these areas in order to determine which processes and sub-processes 
hinder their academic performance. It has a reliability of between 0.50 and 0.82 , and validity of between 0.59 and 0.60 .

This test consists of 9 sub-tests: phonological segmentation, reading letters, reading words, reading pseudowords, understanding words and phrases, prosody, comprehension of texts, writing words, and writing pseudowords.

\subsubsection{Illinois Test of Psycholinguistic Abilities (ITPA)}

The ITPA battery [29] evaluates the psycholinguistic functions involved in the communication process; consequently, it is used in the detection of learning disorders. Each of the 12 sub-tests evaluates the child's psycholinguistic skills at the representative or automatic level. The test has a validity of 0.84 and reliability of between .74 and .90 points.

The main objective of this test is to detect possible failures or difficulties in the communication process (deficiencies in perception, interpretation, or transmission) that are the cause of most school learning problems. At the same time, and in a complementary way, it seeks to highlight the positive skills or conditions that can support a recovery programme. The application is individual and is aimed at children between 3 and 10 .

\subsubsection{Scales for the evaluation of attention deficit hyperactivity disorder (ADHD scale)}

The ADHD Scale [30] evaluates attention deficit hyperactivity disorder (ADHD) and collects information on the child's usual behaviour. To this end, it offers a structured method of observation for the teacher, composed of 20 items that are easy to understand and require a minimum time investment. It has a reliability of 0.90 and validity of .94 points. The evaluator scores the subject using 4 scales: Hyperactivity, Attention Deficit, Attention Deficit Hyperactivity, and Behaviour Disorder.

Cut-off points have been established based on statistical and epidemiological criteria that can help the evaluator make decisions about the diagnosis. These points determine the existence of two levels of risk for the disorder: moderate and high risk. It is a scale for teachers.

\section{Results}

This section describes the results obtained about the qualitative and quantitative assessment discussed above.

\subsection{Biographical Information}

The pupil is a male child, 7-year-and-6-month old, in the second year of Primary Education. No off-setting has been arranged in previous years at school, and he is a pupil with numerous difficulties coping with subjects and in his academic performance

\subsection{Family or Personal History}

Regarding family history, the pupil has an older brother with a mild intellectual disability, but no other history of disability.

\subsection{Information Obtained through the Interview}

The pupil lives with his mother, his two brothers, and grandmother. The pupil's parents are separated and do not have a direct relationship. The pupil has no relationship with his father. He lives in a single-parent family with no daily routines that could create a good educational environment for the child. He has been brought up by his grandmother practically from when he was little, although his relationship with his mother is good and close. He has a good relationship with his brothers most of the time and has never felt jealousy towards them since he is the youngest child. According to the mother, her son has no obligations and does not help around the home. He also spends most of the day outside the home, which does not allow for a proper routine to devote time to studying.

As for the results obtained in the interview with the pupil's family, we can say that there were no complications during the mother's pregnancy or the boy's birth, and that his development has been normal in terms of diet, motor processes, and language acquisition. According to the pupil's mother, his growth development was normal, he was an alert child, he learned his first words very early on (she does not remember exactly when) and the child's behaviour with the family was very loving and well-behaved.

The characteristics of the pupil that the family frequently observes are that he has difficulty with reading and writing, describing him as a lazy child with little initiative for tasks that do not engage his attention. He is a restless, very talkative, an active child according to his mother. He likes to be with children his age and is described as a bit "tiresome" in terms of social relations. The mother thinks that her son acts like "the boss" when surrounded by friends.

As for information from the school setting, the subject is fully integrated in the classroom environment. $\mathrm{He}$ is talkative, restless, and a little lazy. According to his form teacher, the pupil does not show any interest in reading and writing tasks, and is inattentive most of the time. To get him to do the work, the teacher says she must be constantly supervising him, so he almost never finishes what he starts.

\subsection{Results of the Tests Administered}

Regarding his intellectual level, the results obtained in each of the WISC-IV sub-tests are presented in Figure 2, and the composite scores are presented in Table 3. The pupil achieves standard scores in Animals (An), Guessing (G), Similarities (S) and Vocabulary (V). He also achieves low mean scores in Comprehension $(\mathrm{C})$, Cubes $(\mathrm{Cu})$, 
Concepts (Co), Matrices (M), and Letters and Numbers (LN). The lowest scores are obtained in digits (D), Information (I), Arithmetic (A), Coding (Cod), Incomplete Figures (IF), and Symbol Search (SS).

The subject also has lower scores in visual processing compared to verbal processing, along with low scores in working memory and processing speed (see Table 3 ).

The results of the Intelligence Scale indicate that the subject's intellectual capacity is in the LOW-NORMAL zone (IQ 84).

Table 3. Overall scores obtained in WISC-V.

\begin{tabular}{|c|c|c|c|c|}
\hline Index/test & IQ & CS & CI & AC \\
\hline Verbal comprehension & 99 & 48 & $91-107$ & Average \\
\hline Perceptual reasoning & 91 & 27 & $84-100$ & Average \\
\hline Working memory & 82 & 11 & $75-93$ & Low average \\
\hline Processing speed & 82 & 12 & $75-95$ & Low average \\
\hline TOTAL IQ Scale & 84 & 15 & $79-91$ & Low average \\
\hline
\end{tabular}

Note: IQ intelligence quotient. CS Centile score CI Confidence interval. AC: Descriptive category

In summary, the pupil has normal/low overall intellectual functioning, with deficits in working memory and processing speed. He processes and develops information that is transmitted to him graphically and/or visually, which should be taken into account when organising activities with him.

The reading and writing results are presented in Table 4, which shows the pupil's scores on each of the tests. The findings according to the LEE test profile are as follows.

- The pupil has a significant deficit in tasks that evaluate sub-lexical and lexical processes, which is observed in the scores obtained in reading words and pseudowords $(\mathrm{Cs}<10)$. This relates to the data obtained for Reading times, where he achieved a score of $(\mathrm{Cs}<10)$. He has serious difficulties reading words (accuracy and speed), and the scores obtained are significantly below the average expected for his age.
With so many difficulties in decoding processes, the text comprehension test could not be administered since his reading deficits make him unable to read a text.

- In terms of understanding words and phrases, his performance was $(\mathrm{Cs}<10)$, as it was in reading words, which means he is unable to perform the action indicated by the phrase due to the lack of decoding ability in reading. Because he is a child with adaptive capacity, he achieves some results by means of visual association, not by reading.

- The scores obtained in Writing Words and Pseudowords $(\mathrm{Cs}<10)$ reinforce the idea that the main difficulties of this pupil lie in the decoding processes, in this case in the conversion of phoneme to grapheme.

- In terms of his skills in the processes of phonemic segmentation and in the recognition of letters, he is significantly below the expected average.

Table 4. Percentile scores obtained in the LEE Test

\begin{tabular}{|c|c|c|c|}
\hline TESTS & DS & CS & AC \\
\hline Phonological segmentation & 0 & 10 & DIFFICULTY \\
\hline Reading letters & 18 & 10 & DIFFICULTY \\
\hline Reading words & 7 & 10 & DIFFICULTY \\
\hline Word reading time & $3^{\prime} 40$ & 10 & DIFFICULTY \\
\hline Reading pseudowords & 2 & 10 & DIFFICULTY \\
\hline Pseudoword reading time & $4^{\prime} 09$ & 10 & DIFFICULTY \\
\hline $\begin{array}{c}\text { Comprehension of words and } \\
\text { phrases }\end{array}$ & 25 & 10 & DIFFICULTY \\
\hline Prosody & - & - & - \\
\hline Comprehension of texts & - & - & - \\
\hline Writing words & 1 & 10 & DIFFICULTY \\
\hline Writing pseudowords & 0 & 10 & DIFFICULTY \\
\hline
\end{tabular}

Note: CS Centile score CI Confidence interval. DC: Descriptive category

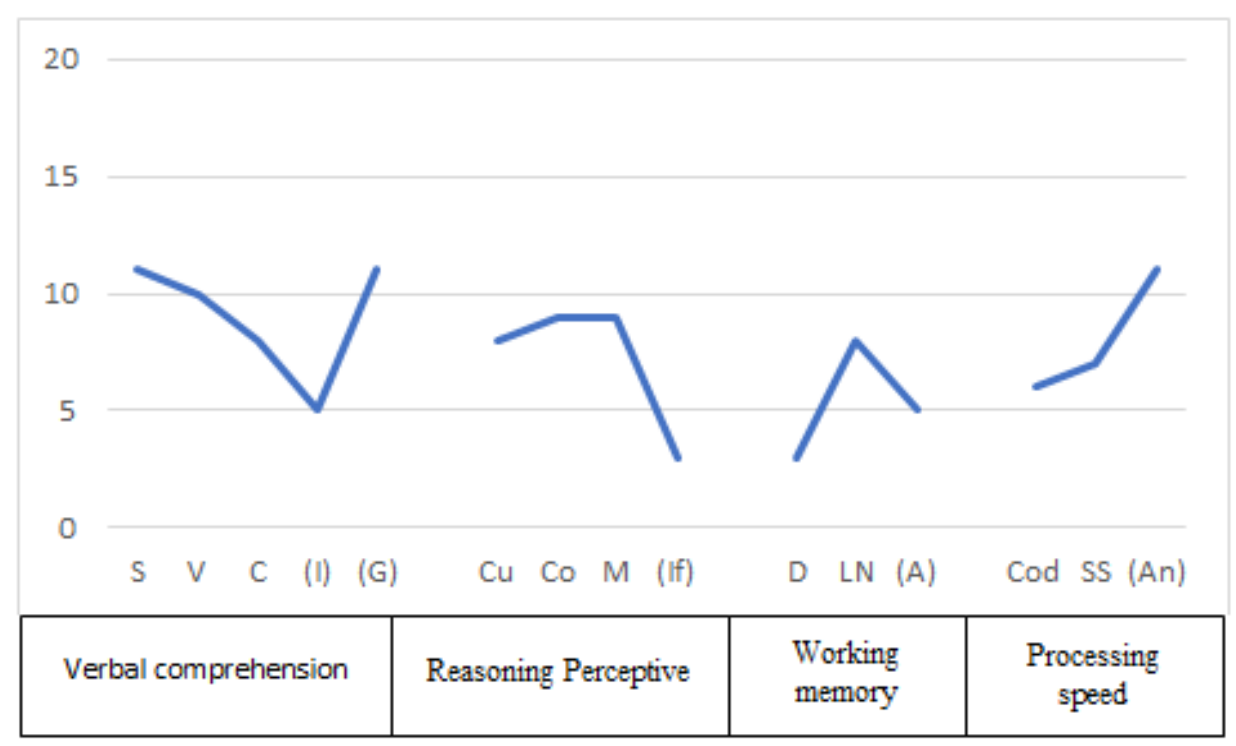

Figure 2. The subject's scores on the WISC scale 
In short, the pupil has problems with:

- Letter identification and phonological segmentation.

- Reading words and pseudowords (grapheme phoneme conversion).

- Reading comprehension.

- Writing words and pseudowords.

- Difficulties in both access routes, so he does not make the proper phoneme to grapheme conversion and has no visual representation of the words. In short, he has difficulty in both the phonological and visual routes.

The assessment of psycholinguistic skills was carried out using the ITPA test, and the scores are set out in Table
5. The pupil has strengths in Verbal Expression (VE), Motor Expression (ME) and Auditory Sequential Memory (ASM), and weaknesses in Listening Comprehension (LC), Auditory Association (AA), Visual Comprehension (VC), Visual Association (VA), Grammar Integration (GI), Visual-motor Sequential Memory (VSM) and Visual Integration (VI).

On the other hand, the pupil gains different scores according to profiles of the aptitudes (see Figure 3), with higher scores for level of expression and moderate scores in association.

Table 5. Results of the ITPA test

\begin{tabular}{|c|c|c|c|c|c|c|c|}
\hline Level & Test & Sub-test & DS & SS & PLA & ST & DS \\
\hline \multirow{6}{*}{ RL } & \multirow{3}{*}{ Auditory vowels } & $\mathrm{AC}$ & 31 & 34 & 7 & & -1 \\
\hline & & AA & 21 & 30 & 6 & & -5 \\
\hline & & VE & 52 & 39 & 8.1 & +4 & \\
\hline & \multirow{3}{*}{ Visual- motor } & $\mathrm{VC}$ & 22 & 34 & 6.7 & & -1 \\
\hline & & VA & 22 & 31 & 6.7 & & -4 \\
\hline & & ME & 29 & 48 & +10 & +13 & \\
\hline \multirow{4}{*}{$\mathrm{AL}$} & \multirow{2}{*}{ Auditory vowels } & ASM & 12 & 38 & 8.5 & +3 & \\
\hline & & GI & 21 & 34 & 7 & & -1 \\
\hline & \multirow{2}{*}{ Visual- motor } & VSM & 11 & 32 & 6.8 & & -3 \\
\hline & & VI & 38 & 33 & 6.1 & & -2 \\
\hline
\end{tabular}

Note: DS Direct Score, SS. Standard score, PLA: Psycholinguistic Age, ST: Strengths, W: Weakness. RL Representative level, AL: Automatic level

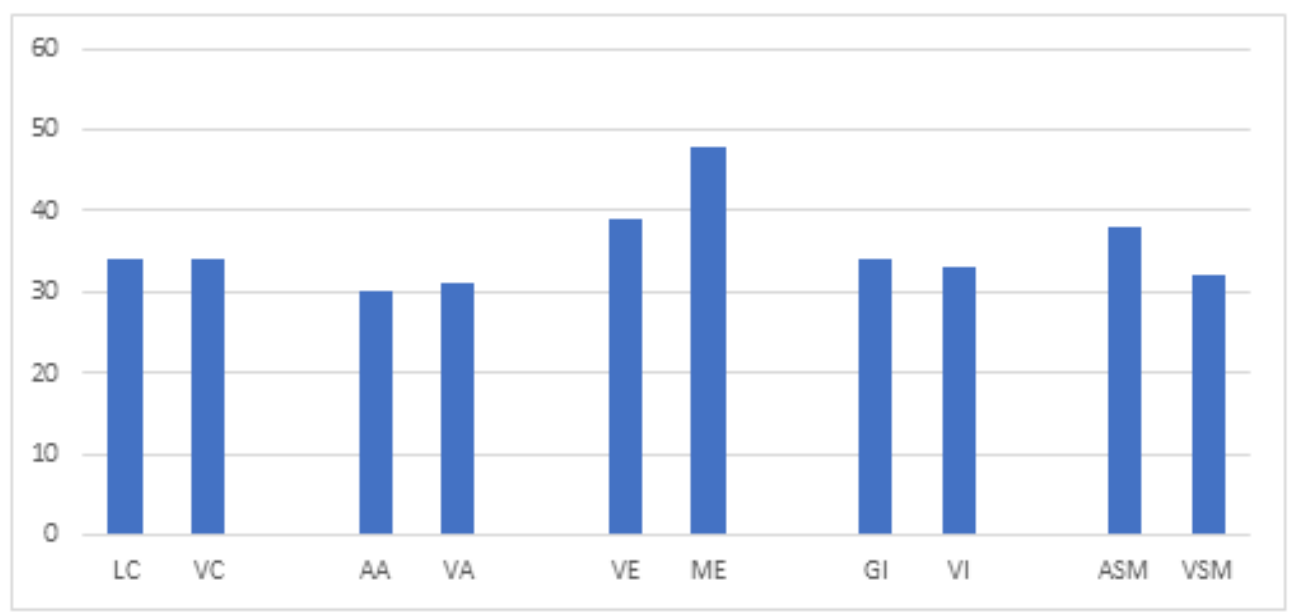

Note: Listening Comprehension (LC), Visual Comprehension (VC), Auditory Association (AA), Visual Association (VA), Verbal Expression (VE), Motor Expression (ME), Grammar Integration (GI), Visual Integration (VI), Auditory Sequential Memory (ASM), Visual-motor Sequential Memory (VSM).

Figure 3. ITPA aptitudes profile 
In short, the pupil obtains low scores on the following tests:

- Visual comprehension.

- Auditory association.

- Visual-motor sequential memory.

- Visual association.

- Auditory integration.

The pupil has difficulties in tests related to each of the levels, i.e., auditory and visual. The overall score obtained corresponds to a Psycholinguistic Age of 7 years and 3 months, which matches his age range, but he has significantly low scores on certain sub-tests.

Regarding the assessment of Attention, the results show that the pupil has a high-risk Attention Deficit (see Table 6), as shown by the centile scores for his age (second year of Primary Education). It should be noted that the pupil presents a moderate risk.

Table 6. ADHD evaluation scores

\begin{tabular}{|c|c|c|c|}
\hline Scale & DS & CS & R \\
\hline Hyperactivity & 9 & 85 & Low \\
\hline Learning Disability & 12 & 95 & High \\
\hline Behavioural disorder & 9 & 75 & Low \\
\hline $\begin{array}{c}\text { Hyperactivity and Learning } \\
\text { Disability }\end{array}$ & 21 & 93 & Moderate \\
\hline
\end{tabular}

Note: DS: Direct Score, CS: Centile score R: Risk

\subsection{Integration of Results and Diagnosis}

Based on the results obtained in each of the qualitative and quantitative tests, the pupil has difficulties in:

- Attention.

- Working memory.

- Processing speed.

- Phonological processing.

- Visual processing.

- Reading (accuracy, speed, and comprehension)

- Writing (accuracy).

Figure 4 provides a clear view of the pupil's deficits, based on the results obtained from the tests administered.

According to the results presented, the pupil displays Reading and Writing Learning Disabilities, so he should take part in an intervention process to re-educate these processes so that in the future his academic performance, which is affected by these disabilities, can improve.

\section{Proposal and/or Development of Psychological Intervention}

\subsection{Description and Justification of the Changes to be achieved with Treatment}

Once the pupil's main deficits have been determined, an intervention plan appropriate to his characteristics is presented in order to improve the reading and writing process. The main objective is to ensure he knows the alphabetical system and can develop his grapheme-phoneme transformation capacity and carry out visual and/or phonological processing. The desired changes are that the pupil can read words and phrases, develop a reading and writing habit that helps him improve his academic performance, as well as improve the attention and memory processes that directly influence this learning.

\subsection{Description and justification of the Target Aspects of Intervention}

In order to bring about the changes described above, a programme is developed aimed at improving phonological awareness, attention, and memory, with a view to developing the pupil's capacity to understand that there is a relationship between phonemes and graphemes, to be able to recognise the different sounds, separate them, associate them, and discover different combinations that can form different words, without a level of distraction that prevents him from concentrating on the task. Work must also be carried out on visual processing.

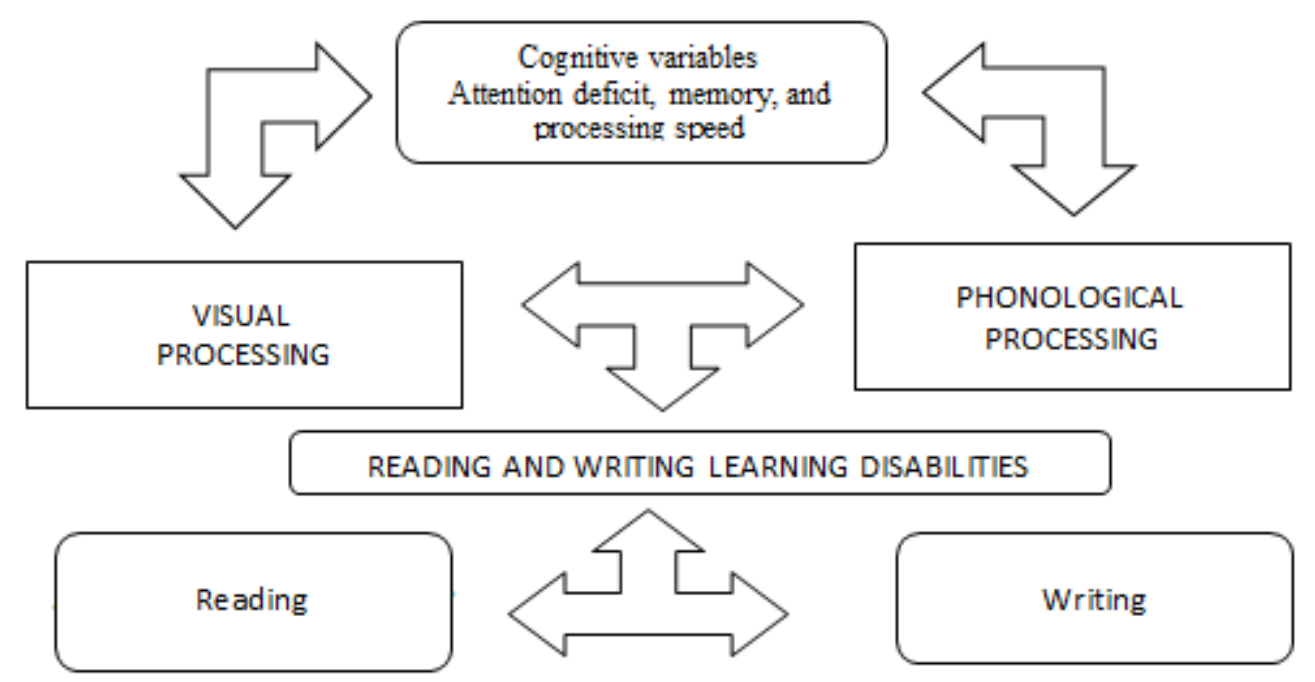

Figure 4. Diagnosis of the case 


\subsection{Guidance for Teachers}

The implementation of the intervention requires the collaboration of the students' teachers, who in general will be guided by the following intervention guidelines [16-17, 31-32].

\section{GENERAL GUIDELINES FOR TEACHERS}

- Special attention will be given to adapting the methodology to the pupil's individual working pace and learning style.

- Therefore, teachers must reduce their demands in terms of speed and quantity of work, and prioritise a slower but more secure learning process.

- Establish priorities: consider what learning, content or activities are necessary for the pupil, and which others do not make sense at a given time.

- Allow for more practice: review and recall, using innovative, varied and always meaningful activities for the pupil.

- Simplify to the maximum: give specific instructions. It is also helpful to divide the work into small units so the pupil can see he achieves targets, showing him what he already knows and what he has yet to learn.

- Using social reinforcement and boosting his self-esteem in relation to learning will lead to an increased effort to learn.

- Assess performance regarding the pupil's own achievements, rather than comparing him with the average performance of children his age.

- Boost self-esteem: most children like this pupil are convinced that they have little chance of success and therefore often think and act in such a way as to avoid making a futile effort. Educators must help them change their perceptions and attributions.

- Anticipate and prevent error: Pupils will learn more if we help them anticipate the mistakes they might make. To do this we can direct the child by means of previous questions or get them used to asking themselves questions before they risk making a mistake. For example, in dictation exercises: the teacher reads the message they are about to dictate, warns of possible "mistakes" that the child might make (even possibly writing them on the board), and then dictates the text.

\section{SPECIFIC GUIDELINES FOR TEACHERS}

The process developed should aim to correct reading difficulties. The child must be re-educated, teaching him reading routes that are effective in understanding what he reads. We must intervene in the acquisition of phonological awareness, in the ability to identify the elements of a sentence. The child is then taught how to identify the syllables that make up a word and identify the sound components of each word, to spell. The next step is to teach "routes to read different words" using spelling recognition. This can be done by giving the child a lot of visual vocabulary. Then we work on the mechanics of reading, including a suitable pace or correct intonation, fundamental to reading comprehension. In parallel, the volume of written vocabulary is gradually increased.

Finally, when the child knows how to recognise the sounds and spelling of words, the written part is worked out, and he can be given help to employ increasingly complex and well-structured sentences for the development of discourse. Written tests and exams should be confirmed with other oral tests. This helps because sometimes children become confused about which question they are answering, because they do not understand the instruction, or when they have to express ideas about what they have learned in writing and in a limited time, which becomes more stressful for them; they do not organise or develop their ideas fully, and texts seem incomplete. Written activities should be planned and scheduled in advance; guidelines should be established to promote the acquisition of word and phoneme awareness.

Here are some verbal activities that could be developed with the child:

- Choose a letter from the alphabet, starting with a letter that appears in the child's name. Throughout the day, look for objects that begin with that letter.

- Make up rhymes for the child's name: "Grace, you have such a lovely face"

- Make the sound of a letter. Ask the child to try and find that letter in a book or newspaper. Read aloud the word that contains that letter.

- Describe the things you see outdoors, using words that begin with the same sound: "huge house", "cute cat", "beautiful boat."

- Make up a rhyme about something: "The bear sat on a chair eating a pear!"

- Choose a song or rhyme that the child knows. Sing it out loud and clap out the rhythm of the words.

- Read with rhyming story with them or sing a song together. Let the child complete the rhyming words.

- Make up two-word rhymes about objects around the house, such as "chair-stair" and "soap-rope." Even better if the rhymes are funny. Some traditional oral language games also develop awareness of sounds: I spy.

\subsection{Guidance for the Family}

To ensure any work done at home is effective in schoolwork, there must be coordination between home and school, and parents must have a close relationship with the school to assist the pupil's education [32].

- Avoid overprotective or rejection behaviours.

- Stimulate and enhance their capabilities.

- Spend time monitoring and checking their homework.

- Reinforce their personal achievements. Assess their work, taking into account the child's pace and difficulties. We must be tolerant and patient. 
- Provide constant affection, support, and encouragement.

- Give them confidence. Mistakes do not matter.

- Believe and convey to the child that success is about working hard and encourage them to make an effort.

- Use things they like or enjoy as a reward.

- Verbalise not only orders and demands but also feelings, sensations, experiences...

\subsection{Criteria Applied When Selecting the Intervention}

The criteria that are applied to select the intervention strategy have depended on the outcome of the psychological evaluation. The major problems he has with reading and writing prevent him from performing well at school. So, it was felt that the intervention should begin by strengthening the processes of phonological awareness, attention, memory, visual processing, and processing speed so that he could shore up his reading and writing process.

\subsection{Intervention Plan}

The potential future intervention plan would consist of a programme to improve attention, memory, phonological awareness, visual processing, and processing speed. The intervention programme would be spread over 24 sessions across 3 months, each session lasting 45 minutes. Each session could be carried out using activities focusing on each process to make it more dynamic [16-17, 20-23, 31-35].

\section{- ATTENTION}

The purpose of these activities is to improve the pupil's ability to focus, which is essential for learning. The main objectives would be to motivate the pupil to focus and propose a sequence to train him in focus and attention.

According to the level of attention deficit displayed by the subject, it is advisable to follow the golden rule, "the greater the deficit, the shorter the duration of the task." Series of activities would be carried out as follows [16-17, 20-23, 31-35]:

i. Discover the path that leads out of the maze.

ii. Do a puzzle.

iii. Do a word search.

iv. Discover missing details in drawings.

v. Draw one animal and not the other.

vi. Complete missing details for drawings.

vii. Look for differences in the two drawings.

viii. Do puzzles with background music.

ix. Arrange the images into a logical sequence, with background music.

\section{- MEMORY}

The purpose of these activities is to develop and improve the pupil's ability to recognise, discriminate, and remember facts and situations. The objectives will be to organise, internalise and retain the information that the subject is constantly receiving from the outside world and to teach him how to use it at the right time. Series of activities would be carried out, as follows [16-17, 20-23, 31-35]:

a Short-term visual memory: a drawing is selected; the pupil must reproduce it, firstly with the model in front of him until it is completed; and then once again without the model in front of him.

b Short-term auditory memory:

- Repeat a sequence of names related to commonly used objects (example: pens, ruler, table...)

- Repeat numerical sequences verbally given by the therapist.

- Repeat numerical sequences verbally in reverse order given by the therapist.

- $\quad$ Play a rhythmic sequence (taps, claps...).

c Long-term visual memory:

- Remember the objects in his dining room at home.

- Describe his school, his bedroom, his living room, etc....

d Long-term auditory memory:

- Learning songs.

- Learning sayings.

- Representation of stories or plays learned by heart, in which everyone must remember their role.

\section{- PROCESSING SPEED}

The purpose of these activities is to improve the child's processing speed in order to improve his overall academic performance. To do this, the following activities will be carried out [16-17,20-23,31-35].

- $\quad$ Reading drawings.

- $\quad$ Putting parts and pieces in the right place with a time limit.

- Answering questions.

- Marking rhythms and beats.

- Making gestures.

- $\quad$ Reading drawings, saying the opposite.

\section{- VISUAL PROCESSING}

The purpose of these activities is to improve the subject's visual processing ability. To do this, the objective is to understand and internalise the visual route to reading and writing. Some of the typical activities would be [16-17, 20-23, 31-35].

- $\quad$ Select and match same and different: differences between geometric shapes, drawings, letters, syllables, words.

- $\quad$ Spot the odd one out.

- $\quad$ Find the missing part of the drawing, from several pieces, prepared for the purpose.

- $\quad$ Find an object in an image.

- $\quad$ Quick word-drawing association; drawing-word 
- Word search.

\section{- PHONOLOGICAL PROCESSING}

The general objective is to develop awareness of the structure of the linguistic message, by mastering lexical, syllable, and phonological segmentation $[4,6,16-17$, 20-23, 31-35].

a Lexical Level

- Lexical segmentation: divide and count the number of words.

- From a story, experience or point of interest, the therapist selects a sentence that is discussed and acted out by the child (example: "Maria eats").

b Syllable level.

- Identify syllables: this will be done through activities in which the child needs to identify and group objects whose name begins or ends with a given syllable, say things that start or end with a given syllable, and draw things that start or end with a given syllable.

- $\quad$ Linking syllables: with this activity, the pupil can visually organise the sequence of the word and be able to obtain another word from one syllable, and so on.

- Missing syllables out: the therapist displays a group of objects and proposes saying their names but missing out the final syllable: "This is called a table, but if we take off the end we would say /ta/".

c Phonemic level

- To carry out this process, fun games and videos will be used to help the pupil learn his letters in a fun way and become interested in reading.

- Isolate vowel phonemes: a group of objects is displayed, and the child says a vowel phoneme and chooses an object beginning with that phoneme /a/; he groups together the objects that begin with the phoneme indicated by the therapist /a/.

- Isolate consonant phonemes: a group of objects is displayed, the child says a consonant phoneme, and chooses an object beginning with that phoneme /f/; he groups together the objects that begin with the phoneme indicated by the therapist /f/.

- Missing out final phonemes from words: the therapist displays a group of objects and proposes saying their names but missing out the final phoneme: "This is called a train, but if we take off the end we would say /trai/".

\section{Discussion and Conclusions}

This paper has analysed a case of learning disabilities. To this end, evaluation techniques were selected to ascertain the pupil's level in terms of intellectual level, literacy, attention, phonological and visual processing.
Having completed the evaluation using qualitative and quantitative techniques, the results, and the proposed future intervention plan, it can be concluded that the case described meets the basic characteristics of reading and writing learning disabilities. Qualitative evaluation together with quantitative evaluation has involved obtaining information to determine the diagnosis and develop the intervention plan.

The subject has a normal/low intellectual ability, but is not able to recognise letters, recognise syllables, read words, and write words. In addition, he presents a range of characteristics, such as memory deficit, attention deficit, and processing speed deficit. These cognitive variables influence visual and phonological processing, preventing the pupil from performing well at school without the external help of a therapist who re-educates his literacy. These results are consistent with the theories and variables mentioned above $[5,16,20]$, which indicate that cognitive and linguistic explanations are at the root of LDs.

The subject does not present intelligence deficits, which agrees with the main LD theories about the irrelevance of IQ in the explanation of RWLD [4-6] but rather as a characteristic of discrepancy between the subject's conserved intellectual capacity and the deficit performance in reading and writing. It has also served as a criterion for the diagnosis of differences with other problems of intellectual disability [18-19].

However, the subject has presented relevant deficits in cognitive variables, mainly in attention and memory. Children with $\mathrm{AD}$ present severe deficits in the processes of control and supervision of working memory, being unable to maintain verbal and / or visual information for their cognitive processing [4-6]. Likewise, they present deficits in the discriminative capacity of stimuli which are unable to select the relevant information, presenting relevant deficits in Attention [16, 21-23], they present comorbidity with ADHD in up to $30 \%$ of cases [4-6].

The main deficits of this subject come from two clearly identified causes: processing speed and deficits in psycholinguistic skills, and specifically, in phonological awareness. These results are in line with the theories of double deficits of dyslexia [36-37], since there is a deficit in the processing speed, which hinders the cognitive processes and prevents the brain connections necessary for the learning of the literacy. Likewise, there are also relevant deficits in phonological awareness, since the subject is unable to isolate the phonemes of the words and to be able to correctly carry out the grapheme-phoneme correspondence processes [20-24].

As demonstrated in various studies, early intervention in phonological awareness promotes development and the learning of reading among children under the age of $6[6$, $16,20]$. For this reason, working on phonological awareness skills is essential, in order to solve possible problems that might arise throughout academic life. From this point of view, it is important for schools to work on 
phonological awareness right from Early Years Education, to avoid problems that might prevent each child from performing well at school. Likewise, it is important to promote the learning of strategies for attention, memory, perception, language and visual-spatial skills $[5,6,16,20$, 38 ] between birth and six years of age, because children acquire skills and knowledge that form the basis on which they can learn skills at school such as reading, writing, and mathematics. The presence of learning disabilities in early childhood may affect the development of these academic skills in the period of compulsory schooling.

Finally, the present study follows a single case design, so the main limitation affects external validity, since the findings are limited to the subject under study. It is difficult to generalize to other populations that differ significantly from the characteristics of the student who was studied. Furthermore, the study is carried out with a Spanish-speaking subject and the possibility of generalizing the results found to other opaquer languages, for example English, should be studied.

\section{REFERENCES}

[1] Ministerio de Educación y Ciencia. Ley Orgánica 3/2020, de 29 de diciembre, por la que se modifica la Ley Organica 2/2006 de 3 de mayo, de Educación [Organic Law 3/2020, of December 29, which modifies Organic Law 2/2006 of May 3, on Education]. Boletín Oficial del Estado, 340, 122868 - 122953, 2020.

[2] Ministerio de Educación y Formación Profesional. PISA 2018. Programa para la Evaluación Internacional de los Estudiantes. Resultados de Lectura en España [PISA 2018. Program for International Student Assessment. Reading Results in Spain]. Secretaría de Estado de Educación. Dirección General de Evaluación y cooperación Internacional. 2020.

[3] Coker, D. L., Kim, Y.S. G. Critical Issues in the Understanding of Young Elementary School Students at Risk for Problems in Written Expression: Introduction to the Special Series. Journal of Learning Disabilities, 51(4), 315-319. 2018. doi:10.1177/0022219417708168

[4] Fletcher, J. M., Lyon, G. R., Fuchs, L. S., Barnes, M. A. Learning disabilities: From identification to intervention. Guilford Press, 2019.

[5] González-Valenzuela, M., Martín-Ruiz, I. Assessing Dyslexia at Six Year of Age. Journal of Visualized Experiments: JoVE, 159., 2020. doi:10.3791/60858

[6] Jiménez, J.E. Dislexia en español. Prevalencia e indicadores cognitivos, culturales, familiares y biológicos [Dyslexia in Spanish. Prevalence and cognitive, cultural, family and biological indicators]. Pirámide, 2012.

[7] González-Valenzuela, M., Díaz-Giráldez, F., López-Montiel, M. Cognitive Predictors of Word and Pseudoword Reading in Spanish First-Grade Children. Frontiers in Psychology. 774, 2016.

\section{doi:10.3389/fpsyg.2016.00774}

[8] Cuetos, F., Suárez-Coalla, P., Molina, M., Llenderrozas, M Test para la detección temprana de las dificultades en el aprendizaje de la lectura y escritura [Test for the early detection of difficulties in learning to read and write]. Pediatría Atención Primaria, 17(66), e99-e107, 2015. doi:10.4321/s1139-76322015000300002

[9] Romero, A., Castaño, C., Córdoba, M. Eficacia de un programa de intervención temprana para reducir las señalas de riesgo de la dislexia [Efficacy of an early intervention program to reduce the risk signs of dyslexia]. Revista Nacional E Internacional De Educación Inclusiva, 9(2), 186- 200, 2016.

[10] Consejo Escolar de Andalucía. Informe sobre el estado y situación del SISTEMA EDUCATIVO en ANDALUCÍA CURSO 2017/18 [Report on the status and situation of the EDUCATIONAL SYSTEM in ANDALUSIA COURSE 2017/18]. Consejería de Educación, 2020.

[11] United States. Individuals with Disabilities Education Improvement Act of 2004. Public Law 108-446, 2004.

[12] Shaywitz, B. A., Sally E. S. The American experience: towards a 21st century definition of dyslexia, Oxford Review of Education, 46 (4), 454-471, 2020.

[13] National Joint Committee for Learning Disabilities. Learning disabilities: Issues on definition. Asha, 33: 18-20, 1991.

[14] National Joint Committee on Learning Disabilities. Learning disabilities and young children: Identification and intervention, 2006. Retrieved from www.ldonline.org/njcld

[15] Horowitz, S. H., Rawe, J., Whittaker, M. C. The state of learning disabilities: Understanding the 1 in 5. National Center for Learning Disabilities, 2017.

[16] González, M.J. Prevención Psicoeducativa de las Dificultades de Aprendizaje [Psychoeducational Prevention of Learning Difficulties]. Pirámide, 2012.

[17] Jiménez, J.E. Modelo de Respuesta a la intervención. Un enfoque preventivo para el abordaje de las dificultades específicas de aprendizaje [Response to intervention model. A preventive approach to addressing specific learning difficulties]. Pirámide, 2019.

[18] American Psychiatric Association. Diagnostic and Statistical Manual of Mental Disorders: DSM-5. Washington, D.C.: American Psychiatric Association, 2013.

[19] World Health Organization. CIE-11. 2018.

[20] González-Valenzuela, M.J. Current Perspectives on Prevention of Reading and Writing Learning Disabilities In C. S. Ryan. Learning Disabilities: An International Perspective.; 63-81, 2017. doi:10.5772/65822

[21] Defior, S., Serrano, F., Gutiérrez, N. Dificultades específicas de aprendizaje [Specific learning difficulties]. Síntesis, 2015.

[22] Soriano, M. Dificultades en el Aprendizaje [Learning Disabilities]. GEU editorial, 2014.

[23] Ortiz, M. Manual de Dificultades de Aprendizaje 
[Learning Disabilities Manual]. Pirámide, 2004.

[24] Katalin, G. V. Special Cognitive functioning in schoolchildren with dyslexia. Magyar Pszichologiai Szemie- 59(1), 41-56, 2004.

[25] Merchán Price, M., Henao, J. Influencia de la percepción visual en el aprendizaje [Influence of visual perception on learning]. Ciencia \& tecnología para la salud visual y ocular, 1: 93-101, 2011.

[26] Bishop, A. G. Prediction of first-grade reading achievement: a comparison of fall and winter kindergarten screenings. Learning Disability Quarterly. 26, 189-200, 2003.

[27] Kazdin, A. E. Single-Case Research Designs : Methods for Clinical and Applied Settings. Oxford University Press, 2011.

[28] Kratochwill, T.R., Levin, J.R. Single-Case Intervention Research: Methodological and Statistical Advances American Psychological Association, 2014.

[29] Wechsler, D. WISC-V: Escala de Inteligencia de Wechsler para Niños-V [WISC-V: Wechsler Intelligence Scale for Children-V]. Pearson, 2014.

[30] Defior, S., Fonseca, L., Gottheil, B., Aldrey, A. LEE: Test de lectura y escritura en español : $1^{\circ}$ a $4^{\circ}$ de educación primaria: manual técnico [LEE: Spanish reading and writing test: 1 st to 4 th grade of primary education: technical manual.] Paidós, 2006

[31] Kirk, S., McCarthy, J., Kirk, W., Ballesteros Jiménez, S., Cordero Pando, A. ITPA: Test Illinois de aptitudes psicolingüísticas: manual [ITPA: Illinois Test of Psycholinguistic Abilities: Manual]. TEA, 2004.

[32] Farré i Riba, A., Narbona García, J. EDAH: evaluación del trastorno por déficit de atención con hiperactividad: manual. [ADHD: Assessment of Attention Deficit Hyperactivity Disorder: Manual]. TEA, 2001.

[33] Outón, P. Programas de intervención con disléxicos: diseño, implementación y evaluación [Dyslexic intervention programs: design, implementation and evaluation]. CEPE, 2007.

[34] Teruel, J. Latorre, A. Dificultades de aprendizaje Programas de intervención en dislexia y discalculia [Learning disabilities Dyslexia and dyscalculia intervention programs]. Ediciones Pirámide, 2014.

[35] Defior S. Como mejorar la lectura [How to improve Reading]. Mente y cerebro. 2015; 70: 16-23.

[36] Graham, S., MacArthur, C.A., Fitzgerald, J. Best practices in writing instruction. Guilford Press, 2013.

[37] Lachmann, T., Weis, T. Reading and Dyslexia From Basic Functions to Higher Order Cognition. Springer International Publishing, 2018.

[38] Wolf, M., Bowers, P. G. The double-deficit hypothesis for the developmental dyslexias. Journal of Educational Psychology, 91(3), 415-438, 2009. doi 10.1037/0022-0663.91.3.415

[39] Moura, O., Pereira, M., Moreno, J., Simões, M.R. Investigating the double-deficit hypothesis of developmental dyslexia in an orthography of intermediate depth. Ann Dyslexia, 70(1):43-61, 2020. doi: 10.1007/s11881-020-00190-1.

[40] Milla, M.G. Atención temprana de las dificultades de Aprendizaje [Early attention to learning difficulties]. Revista Neurológica, 42 (2): 153-156, 2006 